\title{
FUTEBOL FORA DO EIXO: A GESTÃO DO DINOSSAURO VERDE DO SERTÃO
}

\author{
R. J. S. LÔBO ${ }^{1}$, O. G. SILVA ${ }^{2, *}$, T. K M. COSTA ${ }^{3}$ \\ ${ }^{1}$ Universidade Federal do Cariri - UFCA, ${ }^{2,3}$ Universidade Federal de Campina Grande - UFCG \\ orlandosilva@gmail.com ${ }^{*}$
}

Submetido 16/05/2018 - Aceito 12/11/2018

DOI: $10.15628 /$ holos. 2018.7307

\section{RESUMO}

A gestão do esporte e especificamente do futebol conta com desenvolvimentos contemporâneos que transformam a atividade em prática empresarial. Tal realidade pode ser percebida mesmo em pequenos clubes das periferias, ou fora do eixo como aqui se nomeia essas situações. Este artigo tem por objetivo descrever a gestão do futebol no Sousa Esporte Clube, um time de futebol do Sertão da Paraíba, distante mais de $400 \mathrm{Km}$ da capital do estado. Para tanto, se utilizou metodologicamente de entrevistas semiestruturadas junto aos dirigentes do clube e análise de conteúdo, além de técnica de descrição de processos. Os resultados mostram uma gestão que, mesmo fora do eixo, apresenta-se como processo consciente das práticas de mercado e atenta para as definições a serem alcançadas em seus processos cotidianos. Conclui-se apontando para a necessidade de desenvolvimento de profissionais de gestão locais, de forma a perseguir as potencialidades mercadológicas do futebol.

PALAVRAS-CHAVE: Gestão do Futebol, Times Periféricos, Realidade do Esporte.

\section{SOCCER IN HINTERLAND: MANAGEMENT AT DINOSSAURO VERDE DO SERTÃO}

\begin{abstract}
The management of sports and specifically soccer has recent developments that turn the activity into a business practice. Such reality can be perceived even in small clubs in hinterland. This article aims to describe the management of the Sousa Esporte Clube, a soccer team from hinterland, state of Paraíba, in Brazil, more than $400 \mathrm{~km}$ from the capital. To do so, we conducted semi-structured interviews with the directors of the
\end{abstract}

team and analysed its content, drawning on technique of processes description. The results show a management that, even in hinterland, presents itself as a conscious process of market practices. We conclude by pointing to the need for the training of local management professionals, in order to pursue the marketing potentials of soccer in Brazil.

KEYWORDS: Soccer Management, Peripheral Teams, Reality of Sports. 


\section{INTRODUÇÃO}

O Sousa Esporte Clube é conhecido como o "Dinossauro Verde do Sertão" devido ao sítio histórico arqueológico com pegadas de dinossauros existente no município de Sousa, Alto Sertão da Paraíba, distante mais de $400 \mathrm{~km}$ da capital do estado. A cidade possui a alcunha de Terra dos Dinossauros e por isso o símbolo do time é um tiranossauro, verde em função das cores originais do time, que teve seu desenho recentemente incrementado em campanha da Fox Esportes (Fox Esportes, 2016).

A inserção do Sousa E. C. em campanha da Fox Esportes, mesmo sendo um time de "futebol fora do eixo", ou seja, que não está inserido nos grandes centros e nas principais divisões, corrobora a noção de que o futebol é um grande negócio. O futebol se tornou atualmente uma das grandes indústrias em volume de dinheiro, com capacidade de gerar uma gama de negócios que são derivações do espetáculo central, o jogo. O mercado do futebol movimenta anualmente entre $\mathrm{R} \$ 455$ bilhões e $\mathrm{R} \$ \mathbf{5 7 7}$ bilhões, e ainda conta com grande capacidade de crescimento no Brasil (Oswald, 2014).

Dessa maneira, a profissionalização e a qualificação dos gestores de desportos atualmente no Brasil conta com a Lei de № 13.155, de agosto de 2015, conhecida como Lei de Responsabilidade Fiscal do Esporte - LRFE, que estabelece princípios e práticas de responsabilidade fiscal e financeira e de gestão transparente e democrática para entidades desportivas profissionais de futebol através de medidas e práticas que buscam a transparência e a democracia em entidades de futebol, criando também o Programa de Modernização da Gestão e de responsabilidade Fiscal do Futebol Brasileiro, PROFUT, visando o aperfeiçoamento da gestão nos clubes de futebol (Brasil, 2015).

Porém, há que se ver que a estrutura do futebol brasileiro e a forma como ele se organiza pode refletir o padrão cultural das diferentes realidades brasileiras e a ética dual que permeia o futebol com gestores amadores e jogadores profissionais. A institucionalização do amadorismo, entretanto, se contrapõe às forças do mercado que requerem modelos adequados de gestão (Leoncini \& da Silva, 2000). Assim, há a necessidade de se ter estudos que embasem os atores desse campo.

A partir de um movimento instalado desde a década de 1960 nos Estados Unidos, denominado de sport management, e de estudo europeus no mesmo período com enfoque em clubes de futebol e administradores do esporte a área ganha espaço e no Brasil e começa a se desenvolver com o mestrado do curso de educação física da Universidade Gama Filho, estando atualmente a gestão do esporte inserida dentro de cursos de bacharelado em diversas universidades do país (Rocha $\&$ Bastos, 2011).

Assim a proposta desta pesquisa foi responder a seguinte questão: Como se dá a Gestão do Futebol do Sousa Esporte Clube? Delimitando, por conseguinte, o objetivo de descrever a gestão do Dinossauro Verde do Sertão. Para atender a tal intuito o presente artigo está estruturado em mais três seções textuais além desta introdução e das considerações finais. $\mathrm{Na}$ seção 2, a seguir, organiza-se o referencial teórico-contextual sobre a estrutura e gestão do futebol no Brasil e a gestão do esporte. Posteriormente, na seção 3, se descreve a metodologia 
que permite o desenvolvimento do presente artigo. Já na seção 4, traz-se, por fim, a descrição, na forma de síntese de resultado de pesquisa, sobre a gestão no Sousa Esporte Clube.

\section{ESTRUTURA E GESTÃO DO FUTEBOL NO BRASIL E A GESTÃO DO ESPORTE}

O futebol no padrão atual é obra das sociedades competitivas surgidas com a Revolução Industrial (Elias \& Dunning, 1992). Organizado no mundo por meio de federações e confederações, o futebol tem na Federação Internacional de Futebol Associado (FIFA) sua organização de maior abrangência, porém não única, havendo também a Nouvelle Fédération $B O A R D$ (NF-BOARD), uma federação que conta com os países que não são federados à FIFA e em sua grande maioria estados não reconhecidos politicamente em âmbito mundial e cuja influência no futebol é praticamente inexpressiva (Mello, 2015).

A partir da FIFA, a organização hierárquica da gestão do futebol mundial se estrutura em seis confederações continentais filiadas, a saber: Confederação Sulamericana de Futebol CONMEBOL, Confederação de Futebol da América do Norte, Central e Caribe - CONCACAF, União das Federações Europeias de Futebol - UEFA, Confederação Asiática de Futebol - AFC, Confederação Africana de Futebol - CAF e Confederação de Futebol da Oceania - OFC. Cada confederação continental, por sua vez, tem federações nacionais filiadas, assim como estas possuem federações estaduais filiadas. Por exemplo, um time profissional do estado de São Paulo é filiado à Federação Paulista de Futebol, que é filiada à CBF, esta é filiada à CONMEBOL que, por fim, é filiada à FIFA (Lôbo, 2016).

A CBF organiza os campeonatos nacionais das séries A, B, C e D e a Copa do Brasil, além de ser responsável pela direção da Seleção Brasileira de Futebol. As federações estaduais dão prosseguimento à atuação da CBF, sendo os campeonatos paulista e carioca os mais competitivos e ricos do país. Em alguns estados os campeonatos vem perdendo sua relevância ao longo dos anos, principalmente nos que possuem um número grande de clubes na série $A$ do campeonato brasileiro, mas são ainda de grande importância para equipes menores, que estão fora dos campeonatos nacionais (Lôbo, 2016).

Os campeonatos estaduais mais ricos, contam com excelentes patrocínios que custeiam os eventos, além de valores expressivos de cotas de TV, consequentemente, têm possibilidade de oferecerem consideráveis premiações financeiras aos primeiros colocados. As cotas de TV, desde 2011, são negociadas individualmente entre o clube e a rede Globo de televisão, anteriormente a negociação era realizada pelo Clube dos Treze, as cotas constituem uma grande fonte financeira para os clubes. Os maiores contratos de cotas de TV para o campeonato brasileiro são das equipes do Corinthians e do Flamengo que no ano de 2012 tinham uma projeção de auferirem R\$ 84 milhões cada (Maia, 2011).

Após diferentes fases, desde seu estabelecimento como atividade de negócios no começo do século XX, a globalização do futebol profissional promovida pela FIFA na década de 1970 organizou o esporte e proporcionou à atividade uma estrutura empresarial e financeira (Lôbo, 2016). Nos anos 1990, mudanças significativas na gestão do futebol nacional acentuaram suas práticas em direção ao mundo empresarial. Com o fim do passe, resultado das leis 8.672/1993, de alcunha Lei Zico e 9.615/1998 conhecida por Lei Pelé, os jogadores deixaram de ser "propriedade" do clube, bem como os clubes passaram a ser empresas. Os jogadores passaram a 
ter mais autonomia e os clubes mais preocupação em serem eficientes gerencial e financeiramente. Na sequência, em 2003, com a Lei 10.672/2003, ficou estabelecido que os clubes devem a preparar e publicar suas demonstrações contábeis, para serem verificadas por auditores independentes, visando gerar maior transparência (SILVA \& CARVALHO, 2006).

As cifras contemporâneas de contratos entre clubes, jogadores e patrocinadores são vultuosas, assim como a comercialização de jogadores, produtos, experiências e marcas. São diferentes fontes de receita, sendo que a o marketing ocupa um importante espaço nessa dinâmica em função das características midiáticas do espetáculo futebol. A máquina financeira, entretanto, acompanhando a lógica do mundo capitalista, estabelece ao mesmo tempo um inegável abismo entre clubes grandes e pequenos, bem como entre os salários dos jogadores que atuam nesses dois grupos. Em 2012, 82\% dos jogadores no país recebiam até dois salários mínimos, na outra ponta, apenas $2 \%$ recebiam acima de 20 salários mínimos (Lôbo, 2016)

Nas últimas décadas verifica-se um crescimento vertiginoso na chamada indústria do esporte. Porém, estudo com 17 dos 20 clubes do Campeonato Brasileiro série A no ano de 2016 mostra que apenas sete dentre esse clubes menciona remuneração para seus dirigentes nos seus estatutos (Borba, Ferreira, \& Lunkes, 2018), o que indica que mesmo entre grandes clubes há imprecisão ou indefinição sobre esses aspectos. Da mesma forma, a adequação entre estrutura organizacional, aspectos financeiros e procedimentos operacionais é fundamental em qualquer organização, não sendo diferente nos clubes de futebol (Santos, Bronzo, Oliveira, \& Resende, 2014).

Nesse contexto, a profissionalização e a qualificação dos gestores de futebol no Brasil conta atualmente com as orientações da Lei de № 13.155, de agosto de 2015, que estabelece no país a Lei de Responsabilidade Fiscal do Esporte -LRFE, através de medidas e práticas que buscam a transparência e a democracia em entidades de futebol profissional criando também o Programa de Modernização da Gestão e de responsabilidade Fiscal do Futebol Brasileiro, PROFUT, visando o aperfeiçoamento da gestão nos clubes de futebol no intuito de incorrer sobre gestões temerárias no futebol brasileiro. Esse mecanismo, por sua vez, visa também a renegociação de dívidas fiscais e trabalhistas dos clubes, constituindo-se como um processo que procura ajustar um andamento nitidamente complicado principalmente para os grandes clubes em evidência (Silva \& Silva, 2016).

De fato, a essência da gestão esportiva é o equilíbrio das situações financeiras e esportivas dos clubes. Nesse processo, deve-se buscar a sinergia entre a performance esportiva e o posicionamento da marca do clube no mercado, almejando retornos financeiros que, por sua vez, permitem a construção de um ciclo virtuoso que adere à identidade do clube (Rocco Júnior, 2014). A gestão do esporte como um processo que envolve o trabalho em conjunto de pessoas e recursos materiais para se conseguir chegar a resultados satisfatórios tem como ponto de destaque o marketing, o que faz com que tais processos sejam em muito confundidos com o todo da gestão no futebol (Rocha \& Bastos, 2011).

Segue do princípio da força do marketing na gestão esportiva a ideia de torcedores como consumidores, indicando um necessário esforço na parte de relacionamento, com "planejamento estruturado, profissionais e executivos motivados e engajados em projetos de melhorias e inovação, processos eficientes [...] e monitoradas através de relatórios gerenciais gerados em sistemas integrados de informação" (Nakamura, 2015, p. 47). 
Os clubes de futebol têm que definir suas estratégias de marketing junto ao mercado, visando o longo prazo. Por ser uma atividade na qual a informalidade está presente, o processo de tomada de decisão deve estar embasado em competências estratégicas previamente delimitadas, de exploração dos espaços dentro e fora de campo. E a marca deve ser a maior fonte de exploração do clube (Nakamura, 2015).

\section{OS CAMINHOS DA PESQUISA: MÉTODOS}

Buscando responder à questão de pesquisa e atender ao objetivo do artigo acompanhouse o norte do estudo maior que dá origem a este texto, que quanto aos fins se configurou como exploratório, procurando uma "visão geral, de tipo aproximativo, acerca de determinado fato" (Gil, 2008, p. 27) e quanto aos meios como pesquisa descritiva, tendo como universo pesquisado os dez dirigentes do Sousa Esporte Clube.

A coleta de dados consistiu em entrevistas com roteiro semiestruturados, ou seja, na qual foram formuladas perguntas fechadas e abertas, dando aos entrevistados a "possibilidade de discorrer sobre o tema em questão sem se prender a indagação formulada" (Minayo, 2002, p. 64). Foram 19 questões no total, com tópicos estruturados em função do referencial teórico e contextual do estudo nas seguintes categorias: estrutura, funções e delegação de tarefas; tomada de decisão; divisão do trabalho; marketing e patrocínio; política de contratação; rotina; competições; relacionamento com a torcida; e Profut.

Foram realizadas entrevistas no início de 2017 com 04 dentre os 10 membros da diretoria do Sousa Esporte Clube. Cabe ressaltar que a diretoria se compõe toda na base de trabalho voluntário e que os quatro membros entrevistados são os mais frequentes e que estão mais ativamente presentes nas atividades do clube, conforme informação do presidente. Eles são responsáveis pelas mais diversas áreas e também pelo dia a dia tanto no campo quanto na administração.

Apesar de haver um roteiro de perguntas semiestruturado foi necessária a adaptação em vários momentos para uma melhor compreensão do que se pedia e à medida que a conversa se desprendia do que estava sendo perguntado a fim de trazê-la de volta aos pontos pré-definidos.

Com posse do roteiro de entrevista, a princípio obteve-se autorização para usar o nome e falar sobre o clube. Em seguida informou-se aos dirigentes como seria o processo. $O$ primeiro entrevistado foi o vice-presidente do clube, logo em seguida o presidente, na sequência o gerente de futebol e por fim o diretor de futebol do clube.

No tratamento dos dados operou-se uma análise de conteúdo (Bardin, 1977), com uma categorização por meio de uma grade aberta, que pode ser alterada de acordo com o andamento da pesquisa, o que se considera apropriado para pesquisas de cunho exploratório (Vergara, 2012).

Uma vez constituído o corpus, fruto da transcrição das entrevistas, passou-se à codificação e categorização do material, para logo em seguida, na construção do texto, seguir com as inferências e interpretações com trechos das entrevistas realizadas. $O$ trabalho original chegou a um volume de "resultados" muitas vezes maior do que o espaço disponível para o artigo aqui proposto, por isso, para sintetizar a descrição da gestão do Sousa Esporte Clube, colocou-se em prática uma técnica de redação idealizada pelo segundo autor deste artigo e 
inspirada na noção de "texto como laboratório" (Latour, 2005). Nessa prática, o que se procura fazer é construir uma narrativa textual atendendo ao objetivo do artigo e interpolando trechos das entrevistas e considerações dos autores sobre os processos em apreço, porém, sem identificar especificamente cada entrevistado, de modo a formar uma voz "única" a partir de um processo plural de falas. Entende-se que tal situação não é novidade nos textos da Administração, uma vez que "as organizações", trazidas à existência de forma teóricometodológica nos estudos organizacionais desde pelo menos March e Simon (1958), se caracterizam como espécies de macro atores que, como indivíduos, possuem atitudes e posturas identificáveis (Czarniawska, 2008). Dessa maneira, distingue-se a seguir as falas dos entrevistados apenas com ligeiro recuo de texto e fonte menor em itálico.

\section{A GESTÃO DO SOUSA ESPORTE CLUBE}

A administração do Sousa Esporte Clube pode ser caracterizada como composta por: presidente, vice-presidente, diretor de futebol e marketing, diretor financeiro, diretor médico e tesoureiro, porém, nada em termos de funções é fixo, rígido, a administração trabalha em diferentes funções de acordo com as circunstâncias, como um grupo de amigos que se junta pra tocar pra frente uma paixão comum.

Não tem como descrever o que é minha função à gente aqui se reúne tentando a forma que a gente escolheu para resolver as coisas à gente faz desse jeito, todos sempre presentes buscando resolver os problemas, sempre existe problema do dia a dia. Na ata do clube sou diretor... nem me recordo é um cargo lá diretor alguma coisa lá e Rafael se eu não me engano agora é vice-presidente, Danilo departamento médico, se eu não me engano sou diretor de futebol uma coisa assim, mas é como eu tô Ihe dizendo, a gente se junta pra evitar e resolver todos os problemas. Faltou alguma coisa a gente tá aqui presente e vai buscar solução em algum alimento que esteja faltando em alguma coisa e procuramos fazer um cardápio de acordo com o nutricionista para ele passar um cardápio ideal. Não existe isso aqui, todos nós a gente trabalha em conjunto em prol do Sousa, entendeu.

Porém, apesar da união entre os dirigentes, o trabalho que executam é não remunerado, e uma possível remuneração do pessoal administrativo, esbarra, como indica a pesquisa, na existência de outras demandas permanentes e mais urgentes para que o clube possa participar de competições, como é o caso do pagamento em dia de jogadores e fornecedores. A questão da remuneração de dirigentes, como se viu (Borba et al., 2018), não é, entretanto problema só dos clubes pequenos e fora do eixo.

A delegação de tarefas no Sousa E. C. é um processo subjetivo e variado, como era de se esperar numa estrutura que transita entre o informal e o formal (obrigatório) na luta diária para participar de competições e se manter atuando. Contudo, mesmo com toda a informalidade e a característica multitarefas de cada componente da direção há no clube uma rotina de reuniões de decisão.

A primeira reunião que acontece é com o treinador, onde a gente fala de contratações e de alguma questão que caso ele queira opinar, como será o treinamento, academia, se ele concorda com o que a gente já oferece etc. Participei de umas 10 ou 15 reuniões durante o Campeonato Paraibano esse ano, quando é pra tomar uma atitude que vai mexer em alguma coisa dentro do clube, por exemplo: demissão de um treinador, contratação de uma atleta que posição é carente no elenco [...] logística de viagem, problema no grupo, às vezes com o treinador às vezes não, mas sempre tem essas reuniões. 
A questão da capacidade financeira do clube se espelha no trade-off de decisões que envolvem no longo prazo a formação de uma estrutura física mais adequada e no prazo imediato participar das competições.

Muitos dizem "mas o Sousa precisa se organizar fora de campo!" [...] Tem um terreno que pensamos em construir um centro de treinamento, só que se Sousa vai e bota o dinheiro lá, o dinheirinho que tem pra formar elenco, pra disputar e tentar subir de série, subir pra serie $C$ e crescer a cada dia, corre o risco da gente ser rebaixado, porque esse era o dinheiro que tinha pra formar o time.

Ausência de estrutura não é uma realidade apenas do futebol fora do eixo, mas as decisões de estrutura material são apontadas como estratégicas pela direção do Sousa E. C., mantendo o melhor dentro das possibilidades para o time.

Esse ano nós trocamos todo material existente na sede do clube nós fizemos um trabalho através de patrocinadores e parceiros para que nós trocássemos todos os colchões e ventiladores, material em geral da sede [...] Além disso, vários outras no dia de jogo tem todo um processo a ser realizado, as frutas a gente procura só pegar no dia do jogo, para ser frutas frescas para os atletas. Gelo, água, a gente deixa tudo pra última hora para ser tudo o mais fresco possível e para na hora do espetáculo não ocorra nada fora do esperado no cronograma.

Um clube de futebol fora do eixo tem resultados financeiros exclusivamente para a manutenção e evolução de seu trabalho dentro de campo, para o crescimento competitivo. Dessa maneira a saúde financeira é ainda mais importante, porque ela impacta diretamente a formação de uma equipe competitiva que tenha resultados que se revertam em patrocínios e parcerias para viabilizar a manutenção e melhor qualificação do time para os campeonatos seguintes. No Sousa E. C. tudo indica que há nesse sentido também uma forte associação entre a política financeira e o respeito ao pagamento dos salários.

A gente gosta de trabalhar sempre dentro do nosso orçamento, alguns desequilíbrios financeiros que aconteceram com o Sousa geralmente foram imprevistos incontroláveis. A gente tem um elenco de acordo com o que arrecada, pra poder não atrasar por que com salário atrasado ninguém trabalha. O Sousa tem essa preocupação, paga em dia e tem suas contas pagas e tudo organizada em dia e a gente trabalha nesse intuito de dar o melhor para nossos atletas.

Como se sabe, estrutura administrativa e financeira requerem um adequado processo operacional como alinhamento estratégico na atuação das diferentes organizações (Santos et al., 2014). Nesse sentido um dos aspectos a ser destacado é que o Sousa E. C. indica ter a tradição de realizar um trabalho de base com um "auxiliar técnico", que circula como olheiro e realiza captação de novos talentos, além de trabalha-los no clube.

O Sousa investe na base, procura jogador, procura lapidar o jogador, pega o menino pra transformar em atleta, essa ano a gente tem como exemplo o Luquinha um menino de Riacho dos Cavalos que a gente vem fazendo esse trabalho. Tem Goianorte, que foi jogador formado no Sousa e hoje tá na base do Palmeiras. Ai o trabalho de base é responsabilidade dessas duas figuras Pioca e Fael, que tem esses olhos clínicos, já trabalharam para o futebol muito tempo pra fazer essa lapidação desses atletas. Sempre tem esse trabalho e o Sousa se interessa muito, porque revelar jogador hoje em dia é receita, tanto de você tentar melhorar o financeiro como você evitar gasto contratando pessoal de fora.

Mas uma questão que interfere em muitas coisas na realidade do time, segundo seus dirigentes é a política local.

Interfere em tudo, a energia do estádio tava um problema lá e existia uma má vontade do eletricista titular da prefeitura foi preciso o Sousa pagar um eletricista de fora pra dar uma olhada e ele achou o problema, foi consertado e desde então a gente não teve mais problema com a questão da 
energia só que outra parte política é o gramado danificado pelos amadores, essa do gramado essa que eu te falei porque ele não vai proibir os amadores com receio de perder o voto de alguns partidários[...]

Independente dos desafios estruturais e das contendas coma gestão municipal o clube segue, todavia, na captação de patrocínio e parceiros. Esse quesito é muito debatido e é visto como reflexo do que é apresentado em campo, proporcional às vitórias e conquistas, que resultam em fortes parcerias. E assim, noções de visibilidade comercial são exercitadas também pela diretoria do Sousa E. C.

Eu faço um projeto todo ano que engloba as marcas, os espaços da camisa, cartazes que ficam atrás do atleta quando está dando entrevista, dentro de campo o Sousa tem alguns espaços ali na parede, no site oficial, nas páginas do Facebook, quando há alguma notícia relacionada à marca a gente divulga e assim por diante. Mas não é simples não [...] Esse ano conseguimos esse patrocínio que não era esperado, porque não é uma empresa que tem sede na cidade. Essa parceria nos incentivou a partir pra patrocínios de empresas semelhante que tenham sua sede em outra cidades.[...] A gente não costuma procurar muitas empresas, a gente gosta de oferecer um pacote que seja interessante pra $o$ Sousa e pra empresa, pra que ela possa estampar tanto a parte da frente quanto a de traz e se a gente fosse dividir não daria.

Quanto ao marketing, que como se viu chega a ser confundido com a gestão total dos clubes (Nakamura, 2015), o que se vê é principalmente a parte de divulgação e promoção do time se desenvolvendo no básico das mídias sociais e nas rádios locais. A associação entre os dinossauros e o time é vista como um dos fortes apelos de mídia do clube.

É uma coisa que "está" faltando e eu sinto falta é de alguém tomar de conta do marketing do Sousa... [...] A gente trabalha, a gente tem o site, a gente tem as redes sociais que hoje é a grande ação de marketing do momento, a gente procura propagar nós temos uma parceria com uma empresa de marketing, não me recordo o nome, que tem um telão no centro da cidade e sempre propagou os jogos do Sousa e toda ação que o Sousa for fazer procura propagar lá, além dos rádios e sempre que tem os jogos e a gente tem parceria com todos os rádios daqui a verdade é essa a parte de rádio o pessoal sempre fez à mídia no dia de jogo a gente sempre ligou pra participar pra chamar o torcedor sempre de forma gratuita mas utilizamos bastante os rádios pra fazer propaganda.

Por fim, a lógica de adesão ao Profut no Sousa E.C é vista como um processo impositivo que conta com críticas quanto à sua finalidade. Como se viu, de fato a questão envolve as grandes dívidas dos clubes centrais brasileiros (Silva \& Silva, 2016), fato para o qual a direção do Sousa E. C. está atenta e mostra conhecimento da dinâmica.

[...] eu acho assim que todas as leis que são feitas nesse país visam à elite do futebol o Profut foi feita pra proteger os grandes que devem bilhões de reais ao INSS, FGTS, a Corinthians, a Flamengo, a Botafogo, ao Vasco, os times grande do Brasil aos pequenos não tem nada. Criaram aquela Timemania com 80 clubes, nós temos mais de 2800 clubes no Brasil então você não tem no futebol brasileiro uma forma, tem o movimento dos atletas que iniciaram tentando criar uma quarta divisão pra preservar os empregos e quantos jogadores não têm desempregado não sendo na Série $B$ e $A$ "está" desempregado você não tem um projeto amplo pra revelar jogadores. [...] Sousa está com suas certidões em dia e vai aderir à questão do Profut porque está sendo obrigado a aderir, mas o Sousa não precisa do Profut, está tudo em dia.

\section{CONSIDERAÇÕES FINAIS}

Com o intuito de responder ao questionamento desta pesquisa, delimitado por seu objetivo, que foi descrever a gestão do futebol do Sousa Esporte Clube, viu-se com a análise de entrevistas várias dificuldades nesse processo, dentre elas as características de mercado do 
interior que não são de cunho comercial, técnico e estrutural. Porém, notou-se que há conhecimento de vários pontos da administração por parte dos entrevistados e que o grau de envolvimento se desvela nas reuniões de gestão.

Há dificuldades, mas há também uma preocupação com a profissionalização o uso da imagem e divulgação, procura e qualificação de novos jogadores, indicando ser o Sousa E. C. um processo formador de jogadores que pode lucrar com a venda desses atletas a outros clubes e explorando o potencial que o país tem. Por outro lado, por serem assuntos que andam quase de mãos dadas na cidade, política e futebol, essa associação se mostra como negativa em certos momentos para o clube, que depende do poder municipal para uso do estádio e outros fatores estruturais de sua existência.

Cabe ainda dizer que a gestão do Sousa E. C requer um olhar mais específico, detalhado e cuidadoso com relação à legislação brasileira, visto que uma série de mudanças na relação clube/jogador e clube/governo realizou-se nos últimos anos e trabalhos com convênios podem ser formados através das leis de incentivo ao esporte das mais diversas esferas de poder, algo não mencionado nem explorado pela gestão do Dinossauro do Sertão.

Vê-se também que há a necessidade local de que mais pessoas conheçam a área e se interessem pela gestão do futebol, que pode se apresentar como fonte interessante e diversificada de renda. Portanto novas pesquisas poderiam focar na profissionalização do administrador de futebol fora do eixo, que será o responsável por mudanças, evidenciando o fato de clubes de futebol deixarem de ser entes sem fins lucrativos se tornando empresas que gerem lucros aos seus associados.

\section{REFERÊNCIAS}

Bardin, L. (1977). Análise de Conteúdo. Lisboa: Edições 70.

Borba, J. A., Ferreira, D. D. M., \& Lunkes, R. J. (2018). Características da estrutura organizacional dos clubes de futebol brasileiros: o que dizem os estatutos? Revista de Contabilidade $e$ Organizações, 11(31), 47-57. Retrieved from https://www.journals.usp.br/rco/article/view/134462/137765.

Brasil. (2015). Lei $\mathrm{n}^{\circ} 13.155$, de 4 de agosto de 2015. Estabelece princípios e práticas de responsabilidade fiscal e financeira e de gestão transparente e democrática para entidades desportivas profissionais de futebol. Retrieved March 16, 2018, from http://www.planalto.gov.br/ccivil_03/_ato2015-2018/2015/lei/l13155.htm

Czarniawska, B. (2008). A theory of organizing. Cheltenham, UK: Edward Elgar.

Elias, N., \& Dunning, E. (1992). A busca da excitação. Lisboa: Memória e Sociedade.

Fox Esportes. (2016). Mascotes Incríveis: FOX Sports remodela símbolos de times brasileiros. Confira antes e depois I FOX Sports. Retrieved March 16, 2018, from https://www.foxsports.com.br/news/241837-mascotes-incriveis-fox-sports-remodelasimbolos-de-times-brasileiros

Gil, A. C. (2008). Métodos e Técnicas de Pesquisa Social (6th ed.). São Paulo: Atlas.

Latour, B. (2005). Reassembling the social: An introduction to actor-network-theory. New York: 
Oxford university press.

Leoncini, M. P., \& da Silva, M. T. (2000). A gestão estratégica de clubes de futebol vista através do caso Manchester United. In ENCONTRO NACIONAL DE ENGENHARIA DE PRODUÇÃO ENEGEP. São Paulo: ABEPRO. Retrieved from http://www.abepro.org.br/biblioteca/enegep2000_e0066.pdf

Lôbo, R. J. S. (2016). Processos de adaptação e vivências profissionais interculturais no futebol globalizado: Profissionais brasileiros da bola. Tese - Doutorado em Administração, Fundação Getúlio Vargas, São Paulo.

Maia, A. (2011). Confira o novo ranking dos clubes em relação às cotas de TV do Brasileirão. Retrieved May 12, 2013, from https://auvaromaia.com/2011/10/23/confira-o-novo-rankingdos-clubes-em-relacao-as-cotas-de-tv-do-brasileirao/

March, J. G., \& Simon, H. A. (1958). Organizations. New York: Sage.

Mello, M. S. (2015). Futebol Moderno Versus Futebol Romântico: O Esporte Como Instrumento de Materialização do Estado Nacional. In Congresso de Ciências da Comunicação da Região Sul. Joinville: Intercom. Retrieved from http://www.portalintercom.org.br/anais/sul2015/resumos/R45-1095-1.pdf

Minayo, M. C. (2002). Pesquisa social: teoria e método. Petrópolis: Vozes.

Nakamura, W. T. (2015). Reflexões Sobre a Gestão de Clubes de Futebol no Brasil. Jounal of Financial Innovation, 1(1), 40-52. https://doi.org/10.15194/jofi

Oswald, V. (2014). Brasil movimenta apenas 2\% do mercado da bola. Retrieved March 16, 2018, from https://oglobo.globo.com/brasil/brasil-movimenta-apenas-2-do-mercado-da-bola13026765

Rocco Júnior, A. J. (2014). Cultura Organizacional e Gestão de Equipes de Alto Rendimento: Os Casos FC Barcelona, Sporting Club de Portugal e AFC Ajax. Podium Sport, Leisure and Tourism Review, 03(02), 12-25. https://doi.org/10.5585/podium.v3i2.72

Rocha, C. M. da, \& Bastos, F. da C. (2011). Gestão do Esporte: definindo a área. Revista Brasileira de Educação Física e Esporte, 25(spe), 91-103. Retrieved from http://www.revistas.usp.br/rbefe/article/view/16846/18559

Santos, N. de M., Bronzo, M., Oliveira, M. P. V. de, \& Resende, P. T. V. de. (2014). Cultura Organizacional, Estrutura Organizacional e Gestão de Pessoas como Bases para uma Gestão Orientada por Processos e seus Impactos no Desempenho Organizacional. BBR - Brazilian Business Review, 11(3), 106-129. Retrieved from http://www.redalyc.org/articulo.oa?id=123031118005

Silva, J. A. F. da S., \& Carvalho, F. A. (2006). A Lei Pelé e a Governança em Organizações Desportivas: um Estudo Empírico sobre Evidenciação Contábil em Clubes de Futebol. In Encontro de Administração Pública e Governança. São Paulo. Retrieved from http://www.anpad.org.br/admin/pdf/ENAPG208.pdf

Silva, L. do M., \& Silva, L. do M. (2016). Análise da lei de responsabilidade fiscal do futebol brasileiro. Revista Eletrônica Direito e Política, 11(2), 508-533. Retrieved from https://siaiap32.univali.br/seer/index.php/rdp/article/view/9018/5007

Vergara, S. C. (2012). Métodos de pesquisa em administração (5th ed.). São Paulo: Atlas. 